\title{
DEVELOPMENT OF A LOW-COST DRAWING TOOL FOR A PRESS BRAKE
}

\author{
${ }^{1}$ Radek ČADA, ${ }^{1}$ Tomáš PEKTOR \\ ${ }^{1}$ VSB - Technical University of Ostrava, Ostrava, Czech Republic,EU, radek.cada@vsb.cz
}

https://doi.org/10.37904/metal.2021.4117

\begin{abstract}
In engineering practice, there are cases where it is necessary to design a suitable technology for the production of a small number of pieces of parts to achieve a minimum price of one piece of a manufactured part. The paper describes the development of a low-cost drawing tool for the production of a small number of pieces of cover stampings from $2 \mathrm{~mm}$ thick sheet metal from DC04 steel. The most economically advantageous solution was to use a press brake, in the working part of which a simple drawing tool is clamped. The shape of the blank was designed for the cover stamping. The simulation of the drawing process using the CAE program using FEM made it possible to analyze the drawability of the cover stamping using the forming limit diagram of the used sheet and also to analyze the places with the greatest thinning and the risk of cracking. A designed low-cost drawing tool was made. The production of test blanks for drawing the cover stamping was performed by laser beam cutting. The subsequent drawing of test pieces of stampings verified the applicability of the proposed low-cost drawing tool on a press brake. The possibility of drawing intricate shape stampings using a drawing tool attached to the working part of the press brake was verified.
\end{abstract}

Keywords: Drawing, tool, stamping, press, numerical simulation

\section{INTRODUCTION}

In engineering practice, there are cases where it is necessary to design a suitable technology for the production of a small number of pieces of parts so to achieve a minimum price of one piece of manufactured part. In some cases, after selecting a suitable method of production, it is necessary to adjust the shape or even the properties of the component so that it is easier to manufacture with the chosen method of production while maintaining the required utility properties.

For the production of deep or intricate shape stampings, it is necessary to choose deep-drawn steel with good formability $[1,2,3]$. The most frequently used material in the Czech Republic is tempered steel DC04, which is produced by continuous casting [4]. The use of high-strength steel [5] is important, for example, in the manufacture of bodies where low weight is desired. In some applications, the mechanical properties of sheets can be increased, for example, by the unconventional forming method DRECE (Dual Rolls Equal Channel Extrusion) [6]. Proper registration and identification of metallurgical materials are important in a manufacturing company [7].

When designing a drawing tool, it is appropriate to verify its functionality before its production by simulations of the drawing process [8], while the properties of the formed material are characterized by its diagram of ultimate deformations [9]. It is necessary to design a suitable shape of the blank, dimensions and material of the semi-finished product and the method of its division. For stampings of larger dimensions, the law of similarity can be used in simulations of the forming process [10]. The method of deformation networks can be used for the analysis of the material flow in the drawing process [11].

With a low number of stampings, it is not appropriate to choose a standard process of progressive pressing due to the high cost of production of the process tool. In these cases, the development of a low-cost drawing tool for the production of a small number of pieces of stampings is an economically suitable solution. 


\section{COVER STAMPING}

Figure 1 shows the dimensions of the cover stamping with two technological holes on the sides of the central hole and its manufactured model is shown.
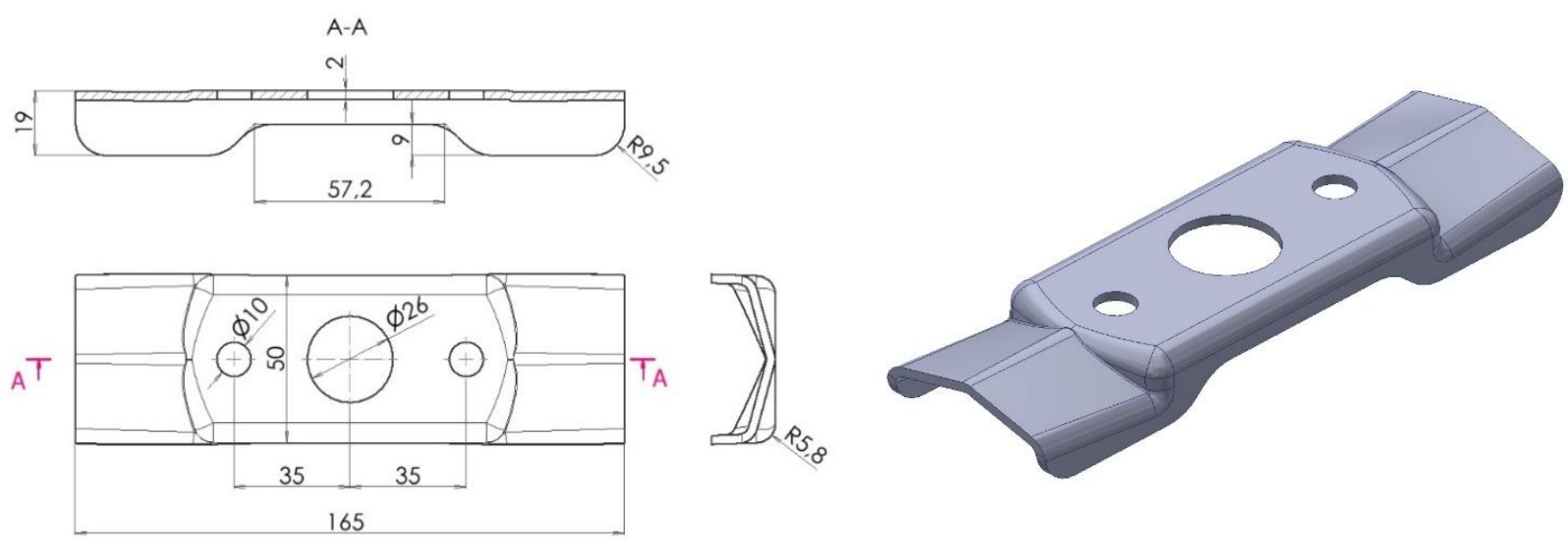

Figure 1 Dimensions and model of the cover stamping with two technological holes on the sides of the central hole

\section{DESIGN OF TECHNOLOGICAL PROCEDURE FOR STAMPING PRODUCTION}

Due to the low number of stampings, it was not appropriate to choose the standard technology of progressive pressing due to the high cost of production of the progressive tool. As an economically suitable solution, the drawing of a complex shape with the aid of a tool mounted in the working part of the press brake was chosen.

For the production of a complex shape of the cover, a deep-drawn steel DC04 (11 305.21) with a thickness of $2 \mathrm{~mm}$ in the form of sheets was chosen concerning the small number of produced pieces.

The choice of a suitable press brake was given by the client's machine park. The DARLEY EHP 80 CL CNC hydraulic press brake was chosen.

\section{CREATION OF STAMPING MODEL AND BLANK TO DRAW IT}

A stamping model was created in Autodesk Inventor according to the production drawing of the cover provided by the client (Figure 1). Two side technological holes with a diameter of $12 \mathrm{~mm}$ were designed by the authors to hold the blank in the drawing tool at the beginning and in the drawing process. Their existence has been approved by the contracting authority because they do not affect the function of the product. The central hole with a diameter of $26 \mathrm{~mm}$ (Figure 1) will be made in the operation following the drawing, thus obtaining greater accuracy of its dimensions than if it had already been made in the blank before drawing. Furthermore, the shape of the blank was generated using the BSE module in the Dynaform program (Figure 2).

\section{DESIGN OF A LOW-COST DRAWING TOOL FOR A PRESS BRAKE}

Due to the low number of required housing stampings, it was not appropriate to choose the standard technology of progressive pressing due to high production costs. The most economically advantageous solution was to use a press brake, in the working part of which a simple drawing tool is clamped. The tool clamping system is approximately the same for all CNC press brakes. The design of the drawing tool for drawing an intricate shape stamping was based on the original WILLA clamping system (Figure 3). This involves clamping the upper press brakes in the ram of the press brake using pins. 


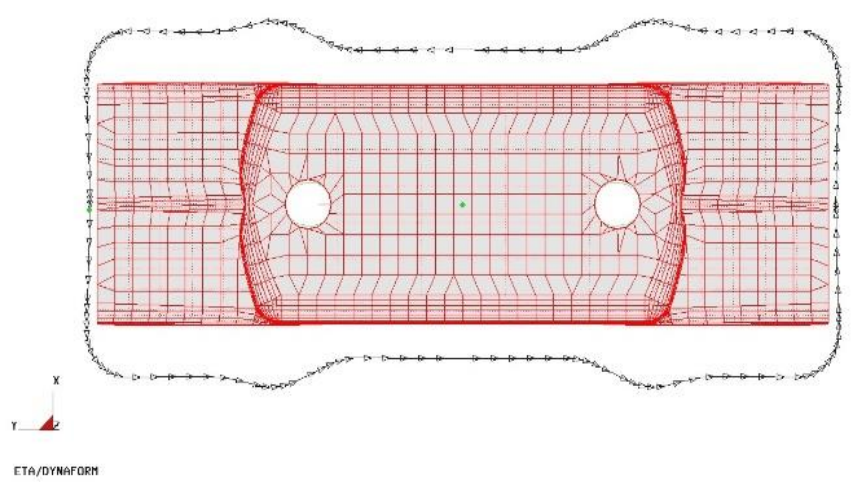

Figure 2 The shape of the blank for drawing the cover stamping determined using the BSE module in the Dynaform program

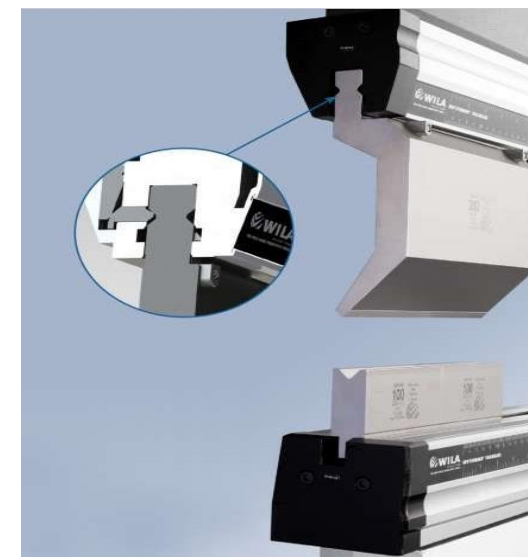

Figure 3 Clamping system of the upper bending bar [12]

The designed drawing tool (Figures 4-6) consists of a punch $\underline{1}$, a die $\underline{4}$, two guide pins of the die $\underline{5}$ and two positioning pins $\underline{3}$ for precise positioning of the blank. The clamping of punch $\underline{1}$ to the ram of the press brake is the same as the clamping of the upper press bar, the clamping of the die $\underline{4}$ to the press table is the same as the clamping of the lower part of the bending tool. Position $\underline{2}$ in Figure 4 indicates the stamping.

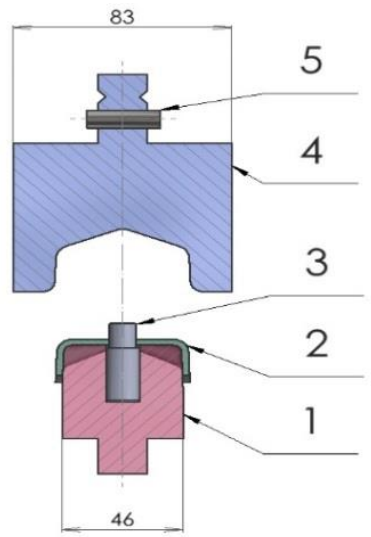

Figure 4 Designed drawing tool for the production of cover stampings

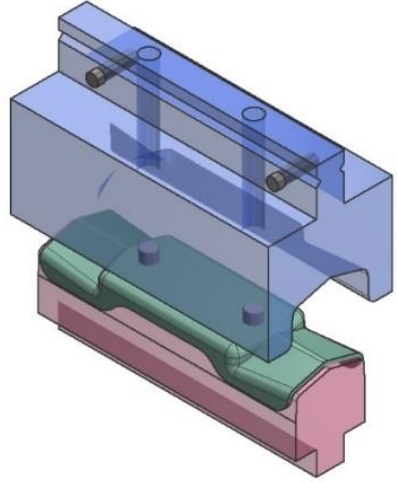

Figure 5 Drawbar model for the production of cover stampings

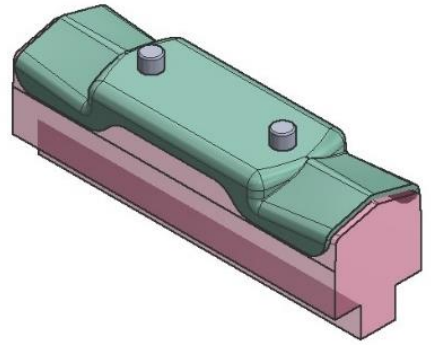

Figure 6 Punch model with two locating pins and final cover stamping model

The procedure for positioning the drawing tool in the press brake is as follows: The punch is inserted into the lower fixed bed (fixed part) of the press brake, using its lower clamping part. The die is inserted into the ram of the press brake, while its correct position is ensured by the guide pins. Subsequently, empty, ie without a blank, is lowered by the ram of the press with the drawing die directly onto the punch, which is then clamped in the lower bed using side screws. In this way, the tool is precisely positioned, clamped and ready to drawing the stampings.

\section{NUMERICAL SIMULATION OF THE DRAWING PROCESS}

To check the design of the working parts of the drawing tool for drawing the cover stamping, a simulation of the sheet metal drawing process was performed in the Dynaform program. 
Since the aim of the analysis was to check the design of the working parts of the drawing tool for drawing the cover stamping, the mechanical and plastic properties of the formed material were taken from the library of materials available in the Dynaform program.

During the numerical simulation, the Krupkowski reinforcement model was used, which is suitable for the description of the hardening of the material of deep-drawn steel sheets:

$\sigma=K \cdot\left(\varphi_{0}+\varphi\right)^{n}$

where:

$\sigma-$ the real stress (MPa),

$K$ - the strength coefficient (MPa),

$\varphi_{0}$ - the elastic real logarithmic deformation (-),

$\varphi$ - the plastic real logarithmic deformation $(-)$,

$n-$ the strain-hardening coefficient $(-)$.

These values were used in the simulations in Dynaform: $\varphi_{0}=0.007848, K=586.3 \mathrm{MPa}, n=0.2474$.

During the simulations, the following input parameters were set: finite element meshes size $4 \mathrm{~mm}$, chord deviation $0.07 \mathrm{~mm}$, shear friction coefficient 0.15 , yield temperature $20^{\circ} \mathrm{C}$, initial sheet thickness $2 \mathrm{~mm}$.

In critical areas of the stamping, where there are large plastic deformations, Dynaform automatically densified the network during the calculation. A simulation of the process of drawing from the blank (Figure 2) was performed and subsequently, the separate analyzes were displayed in the postprocessor.

\section{SIMULATION RESULTS}

After simulating the drawing process in the Dynaform program, an analysis of the compressibility of the cover stamping was performed using a forming limit diagram of the sheet used (Figure 7). From this analysis, it is evident that the maximum values of deformations are in four symmetrical places above the rounded transition to the vertical wall of the stamping near its upper rounded corners.
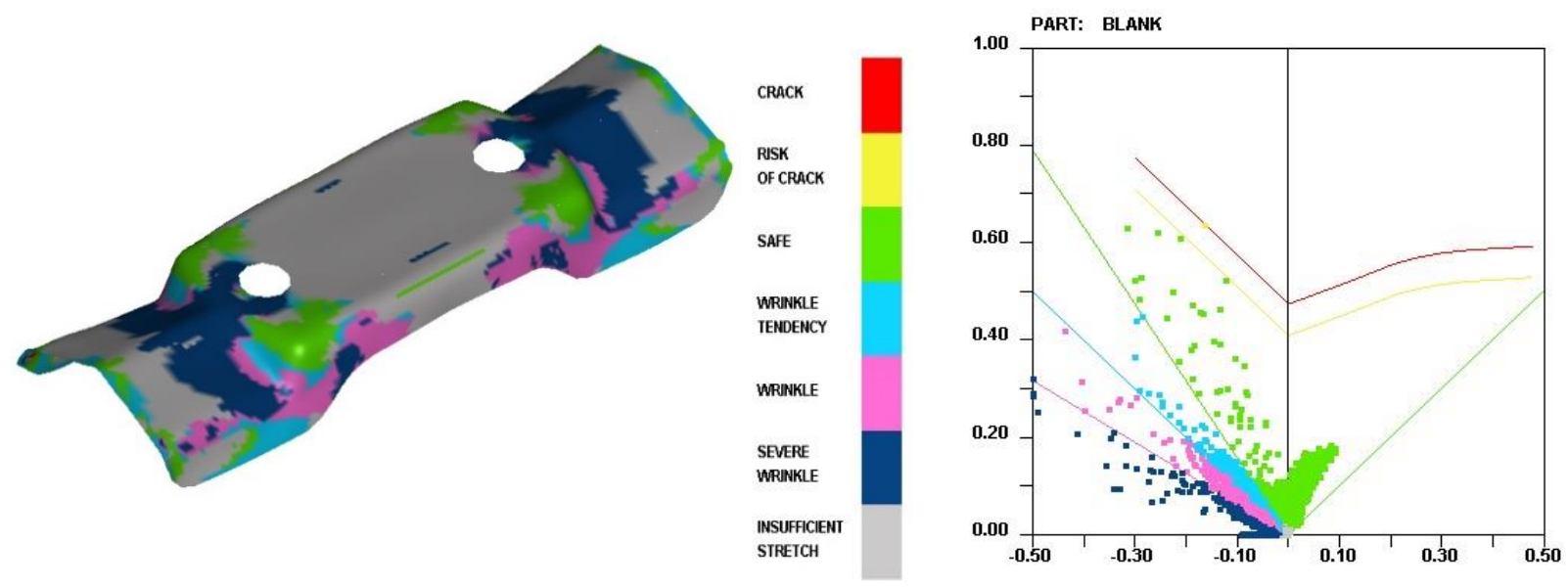

Figure 7 Analysis of the drawability of the cover stamping using the forming limit diagram of the used DC04 low carbon steel sheet

For the given material the analysis of the material thickness after drawing of the stamping (Figure 8), analysis of the material flow of the blank during drawing, analysis of the stress in the stamping during drawing and analysis of the material flow through the deformation network of circles with a selected diameter of $4 \mathrm{~mm}$ (Figure 9) were carried out. 

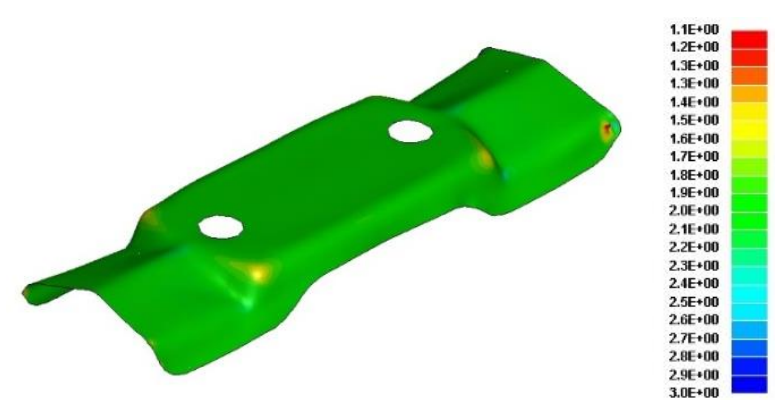

Figure 8 Material thickness analysis after drawing of the cover stamping

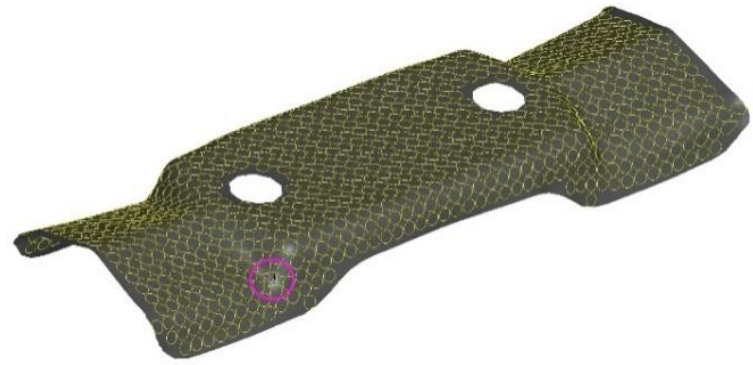

Figure 9 Analysis of material flow through a deformation network with a marked area of maximum deformation

From the analysis of the thickness of the material after drawing (Figure 8) it is evident that its greatest thinning occurs in four symmetrical places above the rounded transition to the vertical wall of the stamping near its upper rounded corners - in these places the thickness is $1.1 \mathrm{~mm}$ after drawing. The highest value of the main stress was in the same places. Analysis of the material flow through the deformation network (Figure 9) made it possible to identify the places of maximum plastic deformation on the stamping - in four symmetrical places above the rounded transition to the vertical wall of the stamping near its upper rounded corners.

\section{MANUFACTURE OF LOW-COST DRAWING TOOL}

Tool steel 19573 (1.2379 according to DIN, X153CrMoV12 according to EN ISO), also known as POLDI $2002 \mathrm{~K}$, was chosen for the production of the punch and die. It is high-performance tool steel of the ledeburitic type for cold work. It is characterized by excellent wear resistance, high compressive strength and good toughness. The steel is secondarily hardenable and is therefore suitable for subsequent chemical-thermal treatment (nitriding, CVD - chemical vapour deposition, PVD - physical vapour deposition). Tool steel 19573 replaces steel 19436 well (1.2080 according to DIN 1652, X210Cr12 according to EN ISO, POLDI 2002), which is also wear-resistant, has dimensional stability with low toughness, is difficult to grind and is suitable for nitriding. Machining of semi-finished products was performed on a five-axis CNC milling machine Deckel DMU 80, while the prescribed surface roughness $R_{\mathrm{a}}=1,6 \mu \mathrm{m}$ was achieved. Heating for hardening was performed in a vacuum furnace. The resulting hardness after hardening was measured with a hardness tester. The determined hardness value of $58 \mathrm{HRC}$ corresponded to the prescribed hardness in the range of $58+2$ HRC. The positioning pins were made of 12060 steel by turning on a conventional lathe with an allowance for grinding on a cylindrical surface, then they were hardened to a hardness (56-60) HRC. Hardening consisted of heating the positioning pins in an electric furnace and subsequent cooling in hardening oil Paramo TK 46/10 (ISO VG 46, ISO 6743). After hardening, the cylindrical surface was ground on a BU 28 grinder with an accuracy of $n 6$ for pressing. The resulting deposit is then $H 7 / n 6$.

\section{EXPERIMENTAL DRAWING OF STAMPINGS BY LOW-COST DRAWING TOOL}

The production of test blanks for drawing the cover stamping was performed by laser beam cutting. The subsequent drawing of test pieces of stampings and their measurement verified the applicability of the proposed low-cost drawing tool on a press brake.

\section{CONCLUSION}

The technology of production of a small number of pieces of the cover stamping was designed to achieve a minimum price of one piece of the manufactured component. A low-cost drawing tool for a press brake was designed. The simulation of the drawing process made it possible to analyze the areas with the greatest 
thinning and to verify the drawability of the stamping. Drawing of test pieces of stampings verified the applicability of the proposed low-cost drawing tool on a press brake.

The possibility of drawing intricate shape stampings using a drawing tool attached to the working part of the press brake was verified.

\section{ACKNOWLEDGEMENTS}

Results in the contribution were achieved at solving of specific research project No. SP2021/104 with the name "Research and Development in Welding, Forming, Surface Treatments of Engineering Materials and Management of Engineering Production" solved in the year 2021 at the Faculty of Mechanical Engineering of VSB - Technical University of Ostrava.

\section{REFERENCES}

[1] ČADA, R. Formability of Deep-Drawing Steel Sheets. In: Materials, Functionality \& Design, Proceedings of the 5th European Conference on Advanced Materials and Processes and Applications EUROMAT 97. Maastricht, Netherlands, 1997, pp. 463-466. ISBN 90-803513-4-2.

[2] EVIN, E., TOMÁŠ, M. Comparison of Deformation Properties of Steel Sheets for Car Body Parts. Procedia Engineering. [online]. 2012, vol. 48, no. 1, pp. 115-122. ISSN 1877-7058. Available from:

https://doi.org/10.1016/..proeng.2012.09.493.

[3] EVIN, E., TOMÁŠ, M., VÝBOCH, J. Prediction of Local Limit Deformations of Steel Sheets Depending on Deformation Scheme. Chemical Journal. 2012, vol. 106, S3, pp. 401-404. ISSN 0009-2770.

[4] VELIČKA, M. et al. Research of Thermal Processes for the Continuous Casting of Steel. Materiali in Tehnologije. 2013, vol. 47, no. 6, pp. 815-818. ISSN 1580-2949.

[5] EVIN, E. et al. The Deformation Properties of High Strength Steel Sheets for Auto-Body Components. Procedia Engineering. [online]. 2014, vol. 69, pp. 758-767. ISSN 1877-7058. Available from: https://doi.org/10.1016/i.proeng.2014.03.052.

[6] HILŠER, O., SALAJKA, M., RUSZ, S. Study of Mechanical Properties of Steel and Selected Types of NonFerrous Alloys after Application of the DRECE Process. In NANOCON 2015: $7^{\text {th }}$ International Conference on Nanomaterials - Research and Application. Brno: TANGER, 2015, pp. 163-167.

[7] SCHINDLEROVÁ, V., ŠAJDLEROVÁ, I. The Importance of Proper Evidence and Identification of Metallurgical Materials for Effective Management of the Company. In Innovative Technologies in Engineering Production (ITEP'18). [online]. Book Series: MATEC Web of Conferences: Volume 244. France, Paris: EDP Sciences, 2018, pp. 1-8. Available from: https://doi.org/10.1051/matecconf/201824401006.

[8] TOMÁŠ, M. Numerická simulácia procesu hlbokého t’ahania. Transfer inovácií. 2011, vol. 20, pp. 129-132. ISSN 1337-7094. http://www.sjf.tuke.sk/transferinovacii/pages/archiv/transfer/20-2011/pdf/129-132.pdf.

[9] NOVÁK, V., VALEŠ, M., TATÍČEK, F., ŠANOVEC, J., CHRÁŠŤANSKÝ, L. The Effect of Strain Rate on Position of Forming Limit Curve. In: $28^{\text {th }}$ International Conference on Metallurgy and Materials (Metal 2019). [online]. Ostrava, Czech Republic: TANGER, 2018, pp. 378-383. Available from:https://doi.org/10.37904/metal.2019.825.

[10] CHRÁŠŤANSKÝ, L.; ŠANOVEC, J.; MARTAWIRYA, Y. Y.; VALEŠ, M. The Law of Similarity and its Application for Numerical Simulation of Sharp Geometries in Stamping. In: $27^{\text {th }}$ International Conference on Metallurgy and Materials (Metal 2018). Ostrava, Czech Republic: TANGER, 2018, pp. 378-383. ISBN 978-80-87294-84-0.

[11] ČADA, R. Evaluation of Strain and Material Flow in Sheet-Metal Forming. Journal of Materials Processing Technology. [online]. 2003, vol. 138, no. 1-3(2003), pp. 170-175. ISSN 0924-0136. Available from: https://doi.org/10.1016/S0924-0136(03)00067-0.

[12] Wila introduces pneumatic clamping systems. [online]. 2015. [viewed: 2021-03-29]. Available from: https://www.canadianmetalworking.com/canadianfabricatingandwelding/product/fabricating/wila-introducespneumatic-clamping-systems 